\title{
DIFERENÇA PURA E NOMADISMO NA FILOSOFIA DA IMAGINAÇÃo DE Giambatista ViCO
}

\author{
[DiFFERENCE AND NOMADISM IN THE GiAMBATISTA ViCo's PHILOSOPHY OF IMAGINATION]
}

\author{
Fabio Henrique Medeiros Bogo * \\ Universidade Federal de Santa Catarina
}

\begin{abstract}
Resumo: A filosofia da imaginação de Vico se destaca na tradição humanista italiana e representa uma verdadeira contraposição ao pensamento racionalista, principalmente pela noção de ingenium, referente à capacidade intuitiva humana de formação imagética e metafórica de sentidos prévios à razão; este conceito, que permite uma revisão do discurso retórico, dos mitos e da própria mediação histórica entre humanidade e mundo natural, opera essencialmente pelo estabelecimento de relações de semelhança entre fenômenos inicialmente dissimilares. Investigam-se associações possíveis entre Vico e as filosofias nômades da diferença de Nietzsche e, particularmente, Deleuze, de modo a revelar que, tanto do âmbito dos conceitos quanto do sentido político de sua obra, a filosofia da imaginação é, à sua própria maneira, nômade e subversiva.
\end{abstract}

Palavras-chave: Vico; ingenium; diferença; nômade; Deleuze
Abstract: Vico's philosophy of imagination stands out in the Italian humanist tradition and represents a true contraposition to rationalist thought, mainly due to the notion of ingenium, which refers to the intuitive human ability of imagetic and metaphoric formation of meaning previous to reason. This concept, which ensues a review of rhetorical discourse, myths and even the historical mediation between humankind and the natural world, works essentially by establishing of similarity relations between phenomena that are apart at first. Possible associations are sought between Vico and Nietzsche's and especially Deleuze's nomad philosophies of difference, revealing that, both from the perspective of concepts and from the political meaning of its work, Vico's philosophy of imagination is nomad and subversive in its own fashion.

KEYwORDS: Vico; ingenium; difference; nomad; Deleuze

A filosofia ocidental historicamente demarcou uma clara cisão entre o $\mathbf{X}_{\text {discurso retórico-patético (referente ao páthos), que intencionava a }}$ produção de um efeito emocional mobilizatório em seu interlocutor, e o discurso lógico-racional, cujo objetivo era o estabelecimento de conclusões lógicas por meio de deduções e conexões entre premissas. O método crítico Cartesiano defendia a produção de um conhecimento produzido pela via lógica-racional, demonstrável e tão isento de páthos quanto possível - o que faria do discurso retórico um modo impreciso, enviesado de conhecimento, que chegava a prestar um desserviço à clareza dos dados de realidade. Ademais, esta mesma tradição filosófica que remete às doutrinas clássicas pós-socráticas desde cedo delineou sua orientação no sentido de pressupostos de organização conceitual regidos por critérios de identidade e semelhança.

* Mestre e doutorando em filosofia pela Universidade Federal de Santa Catarina. Atuação na área da psicologia clínica e docência.m@ilto: fabiohbogo@gmail.com 
Mais de uma dúzia de séculos foi necessária para que a supremacia do pensamento racional pudesse ser fraturada por alguma forma contra-hegemônica de pensamento que se fizesse relevante e, se não legitimada, ao menos considerada como adversário à altura graças à sua coesão e rigor. Embora a grande parte do movimento iluminista não tenha feito outra coisa senão trazer ainda maior sofisticação à faculdade de razão, alguns esforços desta época despontaram em defesa de outras manifestações da atividade intelectual humana. O humanista italiano Giambattista Vico teria sido um filósofo que obteve a superação entre páthos e logos. Se a filosofia crítica Cartesiana não admitia nada que não fosse experimentalmente verificável e ignorava qualquer saber que ultrapassasse estes limites de modo a depurar a possibilidade de equívoco e falseamento de dados, Vico demonstrou que a assunção de uma ideia de verdade absoluta objetificava o sujeito e o mundo em conteúdos verificáveis, mensuráveis, além de rejeitar toda a gama de conhecimentos "secundários" da techné, isto é, da utilização prática no cotidiano.

Vico acusou o pensamento Cartesiano de ter negligenciado o poder criativo da imaginação e da fantasia. Sua filosofia tópica procurou devolver ao indivíduo sua emancipação cognoscente e criativa, e o fez pela formulação de que inventio precede demonstratio, ou a invenção precede a prova (e não o oposto, como se supunha). A filosofia de Vico, nesse sentido, se configurou como uma doutrina da invenção, propriamente, que tecia considerações sobre o conteúdo - o que se diz - e a forma como se diz - do discurso.

Em uma crítica aos racionalistas que julgavam suficiente terem tomado conhecimento de certas premissas fundamentais por meio de relatos e ensino, Vico demonstra o paradoxo de que as premissas originais, por serem subjacentes aos processos lógicos, são indedutíveis por estes próprios processos. $\mathrm{O}$ discurso não seria tornado fértil e inventivo, portanto, enquanto se procurasse identificar uma premissa específica, mas apenas conquanto todas as premissas fossem objetivadas: prudência, imaginação, vida prática etc. Destarte, quando defende uma doutrina da invenção, Vico vai além de Aristóteles, para quem a tópica era tão somente um instrumento de amparo aos argumentos que os ancorava na concretude contingencial da vida prática.

De acordo com Grassi (1990), ao trabalhar com as ideias de "geral" (generi fantastici) e "universal" (universali fantastici) não pensa estes conceitos da maneira como são concebidas no ínterim da lógica tradicional, que é classificatória e subdivisiva. Em vez disso, Vico trata de "retratos ideais", ao modo dos mitos; sua relação com os conceitos intencionados é praticamente oposta à da lógica tradicional, pois a imagem dá conta de uma multiplicidade de sentidos universais concatenados. Sobretudo, a lógica da imaginação de Vico não opera com o mesmo conceito de "teoria geral" que a lógica tradicional: se para esta última o "universal" é produto uma derivação da associação de vários eventos, em Vico o "universal" é uma Gestalt, isto é, uma totalidade pictórica cuja validade é tão imediata quanto transitória, pertencente ao momento do ato e destinada ao seu "fechamento", entendido como a obtenção de alguma sorte de solução para alguma necessidade presente.

De acordo com o autor, o mundo histórico é emergente das interdependências das necessidades humanas que tornam necessária a intervenção no mundo natural. A ação do homem sobre a natureza é, para Vico, uma questão de sensus communis, do âmbito de um julgamento pré-reflexivo e prático antes de ser metafísica, teórica, formal ou filosófica. Isto significa dizer que a identidade humana se constrói a partir de sua busca pelo que lhe é necessário e útil. O que levaria o humano ao sensus communis é sua faculdade de engenhosidade ou inventividade, o ingenium: mais especificamente, trata-se da capacidade de estabelecer relações novas entre conceitos pré-existentes. 
O ingenium é, em Vico, fundador do pensamento mítico: os homens precisam de "deuses", figuras arquetípicas que simbolizem valores e ensinamentos imageticamente, anteriormente à racionalização desta informação. Eventualmente, o homem se dá conta de que os mitos não são senão manifestação de sua habilidade de criação pela linguagem metafórica: eis quando adquire independência criativa (VON BURG, 2010). Se a metáfora e o mito são para Vico a concretização do modo primeiro de conhecimento de mundo, que é a formação de totalidades imagéticas, a figura de Hércules pode ser entendida como a representação da origem da humanidade: ao domar o leão Hércules personifica a primeira "domesticação" humana da natureza. No mito do herói grego Cadmo, por sua vez, o protagonista em certo momento ateia fogo a uma floresta e abre uma clareira onde ergue o primeiro altar em celebração a seu feito intervenção primeva do homem sobre seu ambiente.

$\mathrm{Na}$ literatura filosófica iluminista dos séculos XVII e XVIII o termo ingenium era frequentemente entendido - e traduzido - como "mente". Entretanto, uma análise filológica mais aguçada indica que o uso que Descartes e outros racionalistas faziam do termo não dizia respeito a toda atividade mental: antes, parece-se estar descrevendo a parte do intelecto dedicada à obtenção de certeza racional. Esta apropriação do termo acaba por destituí-lo de seu caráter inovador, descritivo da capacidade de produção de soluções inventivas para problemas práticos. A inventio no racionalismo só poderia ter lugar sob a forma de uma reorganização em um determinado sistema de regras e dados já sabidos. Não haveriam "saltos" criativos, mas no máximo adequações entre relações significativas nas estruturas reguladas da razão de modo a contemplar a solução possível à demanda com o qual o sujeito se deparasse. A descoberta, em Descartes, está diretamente relacionada ao reconhecimento da verdade (DANIEL, 1985, p.237).

\section{DELEUZE E A SUPERAÇÃo DA RECOGNIÇÃo}

O posicionamento discordante que Vico adotou com relação à natureza da inventio o aproxima do outro filósofo que será trazido aqui à guisa de interlocutor: Gilles Deleuze. Em termos de sucessão temporal, ambos não são contemporâneos longe disso. Todavia, o próprio Deleuze (1968) erigiu um argumento em favor do rompimento com o estatuto pré-concebido da identidade de conceitos cujos elementos são hierarquizados conforme seu grau de proximidade e afastamento; antes, o que se cumpre produzir é uma partilha "nomádica", delirante, distribuindo-se por todo o espaço comum subversivamente; este nomadismo subversivo é precisamente ao que Deleuze convida a filosofia e seus agentes, mantendo uma postura de confronto como característica em comum, independentemente da quantidade de séculos que os separem.

Deleuze foi, em suma, um filósofo da diferença, e um contumaz crítico da identidade - e por esta razão seu pensamento parece carregar algo de ameaçador. Enquanto estiver submetida à representação, a diferença inevitavelmente recai na generalidade, que só reconhece aquilo que se conforma às leis da semelhança entre sujeitos e equivalência entre termos. De fato, o termo "reconhece" indica o processo em questão: uma recognição, não-criativa. Em contrapartida, fora dos limites da representação, a diferença perde-se na tangente do "não-ser", no infinito. Ou seja, como ruptura subversiva, a diferença não se deixa representar.

A imagem dogmática, ortodoxa do pensamento, afirma que este é exercido naturalmente, com boa vontade e boa natureza tendendo para a verdade, mas que seria obstruído pelas paixões imanentes do corpo o que justificaria uma mortificação ascética 
do corpo pelo filósofo. Este se ocuparia dos conceitos transcendentes, com um método rigoroso que o permita acessar a verdade. A filosofia se consolida como ciência pura operando dentro dos parâmetros da representação, que não pensa, mas "reconhece". A diferença aparece na lógica representacional apenas como diferença numérica ou específica, isto é, como propriedade da coisa, ou seja, está inserida dentro do conceito é só em Nietzsche e, principalmente, no próprio Deleuze que a diferença receberá o status de conceito em si. A diferença pura - diferença como afirmação - está não apenas na essência do ser, mas também no âmago do pensamento: destarte, Deleuze abdica dos pressupostos da representação com vistas a libertar o pensamento humano de seus liames, e resgatar sua capacidade inventiva - só esta pode atestar a diferença pura.

A tarefa da filosofia da maneira como Deleuze e Félix Guattari (1991) a concebem é operar com os conceitos, inventá-los. Isso pode ser feito por filósofos "sedentários", os metafísicos que corroboram uma leitura estática da realidade e não fazem senão inventariar valores e conceitos pré-existentes, ou também por filósofos "nômades", pensadores da imanência e do devir. Destes últimos, é equivocado inferir que sejam pouco rigorosos ou desordenados por adotarem o caos como paradigma (SCHÖPKE, 2004). Ora, quando a filosofia tentou eliminar a doxa, o conhecimento opinativo, acabou segundo Deleuze (1980b) por universalizá-la elevando-a ao nível racional, assumindo pressupostos inquestionáveis, que "todo mundo sabe", como princípios da filosofia recognitiva. Um filósofo - ou ao menos o que Deleuze chama de um filósofo "nômade" - é o homem de má vontade, aquele que não reconhece os pressupostos implícitos e os suspende para ver o que ali não se via. Elaborando: cada filósofo constrói seu plano de imanência, um espaço por onde os conceitos circulam sem que um e outro se confundam. Ainda que os planos sejam mutáveis, posto que são suscetíveis ao devir, um plano de imanência relevante necessita apresentar coesão interna sustentável. Isto é o que traz rigor ao fazer filosófico. Na analogia de um raio no céu, o raio aparece como figura que se destaca ontologicamente do fundo indiscriminado (céu), ou seja, um não é outro, mas o raio necessita do céu para se manifestar. Em meio ao caos o plano de imanência é um crivo, um corte que o planifica e que, dentro dele, faz circular ordenadas intensivas que são os conceitos.

No caso dos filósofos sedentários e contemplativos, eles adotam como subjacência a seu plano de imanência uma determinada pressuposição imagética de pensamento: alguns princípios que são adotados como "dados", como já-aí, geralmente retirados da valoração moral da razão e do senso comum (como o fato de que a razão é boa, e o caos é ruim, por exemplo). Os pressupostos das imagens de pensamento são implícitos: não estão sequer considerados na obra escrita do filósofo. Tais imagens são da ordem do "inconsciente filosófico", por assim dizer, em contraste com os planos de imanência que sustentam conceitos deliberadamente definidos (SCHÖPKE, 2004). A denúncia feita por Deleuze é a de que, quanto mais afirmam a "pura cientificidade" de uma filosofia desinteressada e benfeitora, mais os filósofos da transcendência moralizam-na com uma ideia pressuposta de "Bem". Foi necessário que alguns filósofos rompessem com esta tradição violentamente, e Nietzsche foi o mais contumaz destes, afirmando o discurso como uma prática nele mesmo. O pensamento se constitui como "máquina de guerra", submetido a uma lógica diferente da do estrato social e capaz de produzir novos modos de existência. Os pensadores "nômades" não pertencem a tradições. É difícil, ou melhor, impossível, classifica-los dentro da corrente filosófica.

A definição do pensamento como máquina de guerra nômade está mais detalhada em Mil Platôs (DELEUZE e GUATTARI, 1980a). A máquina de guerra funciona por uma lógica que é exterior à do estado, embora esteja integrada nele. Ela 
diz respeito não às organizações militares contemporâneas que são braço armado do estado, mas aos guerreiros de outrora, que compartilhavam valores exclusivos ao bando e que não eram de forma alguma os mesmos do camponês, do burocrata e dos sedentários civis em geral. $\mathrm{O}$ fato do filósofo nômade não fazer uso de imagens de pensamento e valores pré-concebidos subjacentes ao seu plano de imanência conceitual é analogamente relacionado ao do guerreiro que se recusa a obedecer aos códigos uniformes da sociedade comum - antes, eles eram singulares, aceitavam o devir e vislumbravam sua própria finitude com destemor. Se desejavam a riqueza, era antes pela abundância e glória do prêmio que pela usura precavida. Quanto ao poder, também não participavam dos jogos políticos internos ao sistema, pois corriam externos a ele, davam-lhe a volta.

\section{DisCURSO RETÓRICO E PRODUÇÃo DE SENTIDO}

Uma vez que se esteja de acordo com a utilização deste marco diferencial para estabelecer dois grandes modos contrapostos de se produzir filosofia, e ressaltando-se o fato de que Deleuze não só faz uso evidente de linguagem metafórica para exprimir esta consideração em termos de uma ocupação territorial como, de modo geral, não se furta em produzir sentidos imagética e engenhosamente, o que resta é um questionamento: será Vico um representante desta classe nômade e subversiva de pensadores à qual Nietzsche e Deleuze se dizem afiliados? E, mais ainda: serão o ingenium, a reapropriação do conceito de retórica e, num espectro mais amplo, a filosofia da imaginação em geral ferramentas conceituais que funcionam como "máquinas de guerra"? Na intenção de sinalizar uma resposta a este inquérito é importante dedicar uma breve reflexão ao conceito de "retórica", que é muito caro a Vico.

Parece haver, grosso modo, dois pontos de vista majoritários pelos quais se pode investigar o conceito de retórica: o modo convencional é tratar da doutrina de um tipo discursivo específico, destinado à persuasão valendo-se de técnicas práticas, "roubando dos ouvintes a liberdade de seu veredito", como disse Kant, que considerava a oratória como indigna de respeito e um estorvo à faculdade da razão. A maneira como Vico a entende, contudo, é a de uma condição filosófica de instauradora do próprio processo de pensar. Esta segunda perspectiva parte de uma análise retroativa do pensar até identificar na gênese do discurso demonstrativo e apodítico os archai, seus princípios últimos que, em si mesmos, não podem ser objeto do próprio discurso racional que originam. $\mathrm{O}$ caráter primário, pressuposto e não-derivativo dos archai, se por um lado impede que estes sejam comportados na lógica racional, por outro indicam ter um funcionamento criativo, analógico: na conclusão de Vico, os archai que regulam todo o pensamento lógico-dedutivo são, eles mesmos, da categoria do pensamento imaginativo. A própria linguagem que é utilizada pelo pensamento racional precisa recorrer a metáforas como "fundamentos", "axiomas" e "clareza" - e até mesmo o termo metáfora é uma metáfora, que tem em seu sentido original a ideia de "transferência" como atividade concreta. Não se pode, contudo, cair no equívoco de pensar que a filosofia da imaginação de Vico seja uma filosofia onírica, restrita ao território dos devaneios; ao contrário, a própria função da imaginação é a ação criativa na natureza com fins de utilidade e de satisfação de necessidades, no processo que recebe o nome de trabalho.

Tem-se em Vico que a imaginação é o primeiro fator a dar sentido(s) ao trabalho. O indivíduo tem uma relação de estranheza para com a natureza, e sua intervenção sobre ela tem o intuito de apreendê-la em redes de sentido, "domesticá-la", de modo a 
neutralizar a ameaça de sua característica indômita, "alienígena"; sendo assim, mesmo tarefas organísmicas mais básicas como a alimentação, o sono ou a procriação sofrem em sua manifestação prática uma considerável ressignificação quando são imbuídas dos sentidos imanentes provindos da imaginação (GRASSI, 1990). O trabalho é, portanto, (re)criação do homem mediada pela sobreposição de necessidades implicando homem e natureza numa relação intrínseca.

O método dedutivo-racional, para o qual o discurso retórico tem valor apenas no campo da didática, como facilitador da aprendizagem, recorre ao formalismo das premissas para lograr abdicar das explicações metafísicas, e por conseguinte ao seu limite autoimposto precisa rejeitar também qualquer traço de emoção ou ipseidade discursiva no tratamento de seus postulados: a retórica é útil nas salas de aula e nos espaços pedagógicos, mas torna-se um estorvo na busca pelo desvelo da verdade, com efeito obstruindo esta atividade - que é "intrinsecamente boa", meta moralizada última da filosofia como ciência pura. Nos termos Deleuzianos remete-se aqui a uma imagem dogmática de pensamento. Não obstante, ao demonstrar que os archai, princípios originários sobre os quais todo o pensamento racional se funda, são constituídos à maneira de metáfora pela capacidade humana de criação e estabelecimento de relações arbitrárias entre as coisas do mundo sensível com fins de satisfação de necessidades, Vico promove uma alternância do objeto da ciência da natureza para a história, e de seu método asséptico para um método fundamentalmente retórico. A verdade não mais seria algo a se deduzir por esforço intelectual, mas sim algo que espontaneamente se manifesta na historicidade dos indivíduos em devir, no continuum de relações com seu ambiente, e poder-se-ia dizer: no engendramento de sentido. As necessidades práticas da humanidade servem de orientação para o trabalho de atribuição de sentido aos acontecimentos e às palavras utilizadas para descrevê-los, e os signos diretivos construídos desta relação estabelecida servem, por sua vez, como orientação para a ação transformadora do ambiente (GRASSI, 1990). Assim, a atividade linguística da metáfora e, por extensão, o discurso retórico que se constrói a partir dela ganham a importância de serem fundadores do mundo histórico humano, tanto como fundamento da inteligência prática cotidiana, o senso communis, quanto na qualidade de fundamento da razão, pelos archai. Nos termos de Stephen Daniel (1985), "o mito e sua forma abreviada, a metáfora, expressam as interrelações dos objetos no nível da gênese do sentido: eles são verdadeiras narrações no sentido de que tal linguagem extrai da experiência indeterminada uma realidade, uma referência".

Esta descrição da relação metafórica interobjetal estabelecida pelo ingenium em muito se assemelha à maneira como Deleuze descreve os conceitos destacam-se diferencialmente de seus planos de imanência conceitual. Os conceitos são formados pelo confronto entre si, em função de responder a determinados problemas; a reapropriação destes não é necessariamente fiadora destes mesmos compromissos, ou seja, virá a atender a demandas de pensamento diferentes. De acordo com o autor, nós "[...] só procuramos a verdade quando estamos determinados a fazê-lo em função de uma situação concreta, quando sofremos uma espécie de violência que nos leva a esta busca" (DELEUZE, 1964, p.15-16). Todo conceito tem componentes, é complexamente construído a partir de outras noções à maneira rizomática de bricolage. A referência que um pensador, neste caso um bricoleur, faz a outros filósofos, deve levar em consideração os problemas dos quais aquele se ocupava, e como o problema do qual este se ocupa encontra eco na obra de seus anteriores (SCHÖPKE, 2004).

\section{ÊNFASE NA SIMILITUDE E NA DIFERENÇA: HAVERÁ COMPATIBILIDADE?}


Mas, de maneira geral, a leitura de mundo da filosofia da diferença não parece coincidente com a de Vico em alguns dos pressupostos mais basilares. Diferenças implicadas umas nas outras promovem um mundo que é caótico, não-identitário. Se sob o ponto de vista representacional o mundo pode oscilar entre categorias de finito ou infinito, no paradigma da diferença ele é paradoxalmente acabado e ilimitado (DELEUZE, 1968).

Há no ingenium de Vico, por sua vez, um aspecto claramente disruptivo: a natureza em si é inventiva, e a engenhosidade humana é, segundo Vico, "aguda" e "penetrante", capaz de perfurar com estruturas convencionais de relações de sentido advindas da associação racional. Todavia, a investida do ingenium não separa ou distancia as coisas. Ao menos declaradamente, não é sua incumbência dar voz à diferença: antes, o que ela perfura não é outra coisa senão as distinções arbitrárias estabelecidas pelas classificações da razão nas quais o mundo fíca compartimentalizado. A observância de princípios racionais da verdade perde prioridade, e sobrevém uma visão do mundo natural plena de relações de similitude possíveis, como uma articulação harmoniosa de fenômenos que permite ao observador trazer - ou evidenciar - a unidade entre dois ou mais deles, por meio da linguagem metafórica e imagética. A mente tópica seria mais abundante e menos verdadeira (VICO, 1725 apud DANIEL, 1985).

O método indutivo herdado do racionalismo consiste na redução da multiplicidade a um fator comum que sirva de "teoria geral"; por contraste, Vico abdica da necessidade de formulação de quaisquer teoremas formais com validade estendida, em favor da caracterização de um processo de "indução de similaridades" que, pela via do pensamento metafórico, opere constantemente a identificação de relações de similitude entre as necessidades prementes e as condições percebidas no ambiente para satisfazê-las. A natureza aqui é percebida como uma realidade a ser definida e ajustada; pela distinção da noção de "trabalho" entre o sujeito (trabalhador) e a natureza (coisa trabalhada) é que Vico resolve a questão cartesiana de sujeito - objeto. Desta forma, o sensus communis tem como valor instrumental a identificação de características objetivas de manipulação da natureza: que materiais podem ser percebidos, quais são inflamáveis e quais não o são etc. Para um indivíduo, não dispor de capacidade imaginativa seria tornar-se um mero reprodutor de ideias: o indivíduo as receberia, decodificaria e transmitiria adiante acriticamente. Graças à faculdade de engenho humano, transcender os limites da recognição está à disposição de qualquer indivíduo, no sentido de associações criativas entre objetos e fenômenos na vida cotidiana.

Em Deleuze, sua caracterização da diferença vem intrinsecamente associada ao conceito análogo da repetição. Todavia, o filósofo subverte o sentido comumente atribuído a este termo operando uma distinção entre a repetição e a generalidade. Enquanto estas últimas são representacionais, associadas por equivalências quantitativas ou por semelhanças qualitativas e com a característica de possibilidade de substituição ou alternância entre seus termos, a repetição é aquela de algo absolutamente insubstituível (DELEUZE, 1968). A generalidade é a linguagem das ciências e das leis, mas a repetição é a linguagem lírica, cujos termos podem ser repetidos, mas não substituídos. A repetição ocorre como uma transgressão, da ordem do milagre, pois ela é "contra a lei" da natureza, contra a equivalência e a semelhança. A ação habitual, a prática de atos cotidianos que se assemelham entre si, é da ordem da generalidade. Nada se repete ali em aparência, senão em níveis menos acessíveis, e há, no máximo, uma "pseudorrepetição" do geral. Só é possível falar em repetição Deleuziana da diferença pura - e esta é a interpretação que Deleuze faz do próprio Eterno Retorno de Nietzsche: o retorno da diferença e não do mesmo. Singularidades 
retornam; no entanto, como singularidades, cada uma delas é única, insubstituível.

Toda mente inserida no meio linguístico é capaz de estabelecer juízos, elaborar representações e reconhecer padrões de semelhança. Este é o movimento natural do intelecto humano. A particularidade dos livres-pensadores nômades que Deleuze descreve é a capacidade de ultrapassar a função do ingenium intrínseca ao ser humano a formação intuitiva de imagens da percepção - em favor da construção arbitrária, forçosa de um pensamento que dê morada à diferença, que ouse criar novos parâmetros por meio de uma ética. Sobretudo, o pensamento é um puro refinamento da razão. É o que permite a ele liberar e produzir a diferença rompendo com a representação clássica. Sua "vontade de potência" exige um esforço deliberado de ruptura com um determinado estado de coisas, um acontecimento extraordinário que produz novidade em um mundo de igualdades e semelhanças do senso comum. Em tempo: esta distinção não implica que o pensamento diferencial seja privilégio de poucos - esta seria uma realidade lamentavelmente desesperançada que invalidaria os próprios esforços de construção de formas de pensamento libertadoras, já que na maioria dos casos pouco ou nada haveria ali para se libertar. Os livres-pensadores não o são por destino ou predisposição genética, mas por, em decorrência de uma série de construções imanentes de sentido histórico, terem se tornado párias e assumido uma perspectiva deliberadamente extemporânea e extrínseca ao estrato social, de modo a poder fazer a crítica deste mesmo estrato.

Isso posto, seria esta arbitrariedade intelectual que Deleuze denomina "pensamento nômade" uma forma de uso criterioso do ingenium? Presumivelmente sim. Afinal, se a diferença pura não pode ser representada, sua apreensão é pré-racional e intuitiva. A questão é que no pensamento nômade o ingenium parece não se prestar à formação de imagens por semelhança e associação de ideias, mas sim pelo seu oposto, a produção de intensidades de sentidos imanentes que dão vista à diferença que vibra nos corpos. Antes dos significados, que são objetos mentais do campo da linguagem, a faculdade de ingenium se presta a apreender os sentidos, como quase-existências, isto é, acontecimentos nas relações entre corpos. Ademais, o contrário também é verdadeiro: o estabelecimento metafórico de relações de similitude pelo ingenium não é senão uma criação a partir da diferença, do devir: o que se produz imageticamente não é uma identidade conceitual que se preste à referência a outros conceitos pré-existentes por parte da razão atendendo a critérios de semelhança; antes, cada imagem é a manifestação de uma diferença pura, afirmativa. Em vez de uma falta que se subtraia à completude do conceito, a diferença evidenciada em uma imagem fruto do ingenium é um acréscimo à comunidade de sentidos que a humanidade produz no devir da história. Como afirma Von Burg (2010, p.44), “o aspecto-chave do ingenium de Vico é a habilidade de conectar os lugares-comuns e metáforas que já compreendemos com o conceito que estamos tentando criar, de modo que o novo pareça antigo e o antigo torne-se novo".

\section{Protofilosofia e Contrafilosofia}

Em última análise, mesmo o foco no estabelecimento de relações de similitude em um dos filósofos e na defesa de um pensamento que dê voz à diferença pura sem constrange-la nas limitações da identidade conceitual em outro, ambos não são mutuamente excludentes. A questão parece ser que um e outro filósofos tecem seus conceitos em âmbitos diferentes, e não intencionam responder ao mesmo problema.

A atividade cognitiva da lógica racional é da alçada de uma epistemologia ou, ao 
menos, de uma filosofia da mente; Mas aquelas outras atividades das quais Vico se ocupou, que são pré-racionais - a imaginação, a retórica e a arte tópica - são relegadas a um status de protofilosofias; com efeito, demasiado frequentemente isto fez com que estas faculdades fossem valoradas como caprichos, indulgências da mente quando não se ocupava prioritariamente das funções que de fato importavam: não é surpresa que o aspecto criativo, produtivo do ingenium tenha negligenciado, e que a própria faculdade de imaginação humana não tenha sido tomada na integridade de seu potencial.

O primeiro objeto da mente é a construção de uma imagem pré-racional que integre metaforicamente toda uma miríade de sentidos sobrepostos. A metáfora é a primeira totalidade que se deixa conhecer, e a qual se permite reclamar conhecimento e associabilidade. Apenas posteriormente é que esta totalidade de sentido rudimentar, protofilosófica, acrescenta-se ao conhecimento empírico da humanidade como senso comum, torna-se aquilo que "todos sabem"; ou, então pode vir a ser substituída pela inteligibilidade lógico-racional e representativa. Como civilização, a humanidade também operou desta forma, criando primeiramente os mitos explicativos da realidade, até dar-se conta de que eram eles próprios os autores desta atribuição de sentidos (DANIEL, 1985). De todo modo, o discurso de conhecimento intuitivo das coisas é prévio ao discurso dos juízos lógicos sobre elas; este último, contudo, torna o falante autoconsciente das estruturas formais regulatórias da própria linguagem, distanciando-o do fato de que esta é metaforicamente criada para atender a quaisquer sortes de necessidades concretas que se apresentem.

Não se pode furtar ao fato de que o que se desdobra subsequentemente à criação metafórica do ingenium é a construção de imagens dogmáticas de pensamento, as mesmas cuja necessidade de ruptura Deleuze atesta como pré-requisito para a tessitura de uma filosofia nômade. Deveras, ou elas constituem os archai que virão a fundamentar o pensamento representacional científico, ou os mitos plurissemióticos sobre os quais se constrói dinamicamente o sensus communis. Poder-se-ia ainda prosseguir nesta arguição tomando de empréstimo a análise Deleuziana da quádrupla sujeição da representação: a identidade no conceito (por exemplo, o conceito de animal), a oposição no predicado (que é própria da diferença específica aristotélica, como no caso da diferença predicativa "animal cavalo" e "animal humano"), a analogia no juízo (relativa à adequação e distribuição do conceito aos termos: "este cavalo é um animal, e também aquele homem"), e, ressalta-se aqui, a semelhança na percepção (DELEUZE, 1968, p.43). Esta última modalidade, nestes termos, confere ao ingenium uma função imprescindível, e parece agrilhoá-lo inexoravelmente aos interesses da sujeição representacional.

Todavia, em defesa de Vico, é preciso ressaltar que, em seu estágio protofilosófico, as imagens intuitivas são o que há de mais nômade: puras potências. Elas são a concretização, a disposição em ato (ainda que atos de pensamento) de virtualidades da ordem da relação diferencial entre as coisas do mundo. Neste sentido, são acontecimentos absolutamente imanentes, próprios das possibilidades que esta realidade oferece; enfim, é sabido que o ingenium é a função originária do pensamento lógico e das representações e dos conceitos estáticos do entendimento, mas esta função viabiliza igualmente toda a atividade de pensamento que é inimiga da razão clássica, contemplativa - esta, sim, atemporal e recognitiva.

O problema da diferença em Deleuze, todavia, é localizado ainda mais primordialmente que o do engenho: mais que inquirir sobre as origens imagéticas do pensamento, a filosofia da diferença é uma observação sobre a natureza diferencial do próprio mundo. É no sentido de uma ontologia radical que Deleuze intenciona operar uma reversão do platonismo, que consideraria a existência do Uno original do qual os 
objetos do mundo material funcionariam como cópia, sendo que aqueles que falhassem em reproduzir com fidelidade todas as características do modelo essencial não seriam senão "cópias ruins" ou simulacros. É preciso, afirma Deleuze (ibid., p.72) romper o primado do original sobre a cópia, pois o mundo atual é o dos simulacros: objetos que subsumem em si a diferença. Pelo eterno retorno, aquilo que retorna e se repete não tem identidade pré-formada. A diferença não está entre a coisa e suas cópias, mas "a coisa é o próprio simulacro" (ibid., p.72) e cada simulacro é um momento da diferença repetindo-se imanentemente, só existente em sua configuração material no aqui-agora.

A faculdade de pensamento e também a arte são ambas ferramentas nômades da contemporaneidade, ao menos na medida em que sua produção provoca impacto, incomoda, perturba a ordem vigente. Nietzsche (SCHÖPKE, 2004), talvez o primeiro desta ampla corrente de pensadores nômades, dedicou-se a fazer ruir as estruturas ancestrais dos pressupostos filosóficos herdados da era clássica. Não é surpresa, portanto, que dado que a filosofia sempre esteve tradicionalmente do lado da manutenção do estado e da civilidade, o que Nietzsche criou assumiu os ares de "contrafilosofia": seu pensamento-ferramenta desprezava as convenções e quebrava as codificações operadas pela lei, pelo contrato e pelas instituições. No que diz respeito à insubordinação ao pensamento filosófico hegemônico, a proposta ousada de Vico, qual seja, operar um desvio naquilo que se considerava a meta última da filosofia do conhecimento, foi particularmente ilustrativa. A filosofia que contempla a razão, de onde vem o conhecimento do verdadeiro, é inapta a considerar a gênese ou origem dos sentidos contidos no âmago da estrutura linguística, porque este sentido é oriundo da arbitrariedade livre, criativa e engenhosa da humanidade. É tarefa da filosofia, então, estudar aquilo que o ingenium humano produz, qual seja, não o conhecimento do verdadeiro, mas a consciência do certo, como aquilo de que se tem certeza intuitivamente. (VICO, 1725, apud DANIEL, 1985). Esta crítica indica uma insatisfação de Vico com o sedentário, o contemplativo. Estaria ele reivindicando uma nova filosofia?

\section{Conclusão}

O que legitima que a filosofia de Vico seja denominada verdadeiramente "humanista", longe de corroborar a crítica frequente e equivocada que se faz desta corrente filosófica de que ela necessariamente pressuponha uma essência humana transcendente, é precisamente que a concretização existencial dos acontecimentos se dá pela capacidade singular do humano de adaptar-se em função das necessidades que reconhece na mediação com o mundo natural e, neste processo, produzir espontânea e instantaneamente totalidades inteligíveis de sentido. Esta capacidade que nos é tão intrínseca, que Vico denomina ingenium, constitui a própria motriz da evolução histórica humana.

Localizar o pensamento imaginativo na origem arcaica da própria razão é, em si, um ato de considerável insubordinação; uma filosofia nômade e crítica dos sistemas de pensamento preponderantes, contudo, não se faz levianamente, mas com coesão interna e rigor redobrados, sob o risco de ter sua assertiva nulificada pelo estrondo da corrente hegemônica que flui na contramão. A mediação homem-mundo que é análoga à metáfora consiste no estabelecimento de conexões entre as necessidades humanas e a percepção da qual um indivíduo dispõe sobre suas condições de satisfação no contexto próximo. Esta análise confere ao termo sensus communis o caráter privilegiado de pensamento pré-reflexivo e fundador do conhecimento, o que é muito distinto do modo 
banalizante como o racionalismo identifica este conceito, qual fosse, um conhecimento "menor".

Desta feita, Giambattista Vico produziu, à sua própria maneira, e dentro de seu próprio contexto, uma filosofia que se pode chamar de nômade: seu plano de imanência conceitual, além de ter conflitado diretamente com todo um massivo movimento filosófico racionalista que lhe foi contemporâneo, abria espaço para a consideração da inventividade que tanto fora negligenciada. Embora o filósofo tenha amparado o aspecto da diferença apenas até certo ponto, não se pode simplesmente deslegitimar seus esforços como se ele houvesse, por seu próprio dolo e suposta má-fé, dado seu raciocínio por encerrado na barreira confortável da semelhança; antes, a própria associação plurissemiótica nas imagens é produção diferencial de sentido imanente. Por mais que uma análise comparativa das teorias suscite esta revelação e corrobore o esforço de superação do paradigma do conhecimento como recognição, que aproxima Vico de outros "filósofos-martelo" como Nietzsche e Deleuze não é, prioritariamente, alguma similitude conceitual específica; antes, eles têm em comum o fato de transformar sua obra em "máquina de guerra", que desmonta conceitos e valores em vez de inventaria-los, e faz de Vico um verdadeiro espasmo revolucionário dentro do movimento humanista italiano.

\section{REFERÊNCIAS BIBLIOGRÁFICAS}

DANIEL, S.H. The Philosophy of Ingenuity: Vico on Proto-Philosophy. Philosophy and Rhetoric, Penn State University Press, vol. 18, n.4, p. 236-243, 1985.

DELEUZE, G. (1962). Nietzsche e a filosofia. Tradução: Edmund Fernandes Dias e Ruth Joffily Dias. Rio de Janeiro: Ed. Rio, 1976.

. ( 1964). Proust e os signos. Tradução: Antonio Piquet e Roberto Machado. 2.ed. Rio de Janeiro: Forense Universitária, 2003.

. (1968). Diferença e repetição. 2.ed. Tradução: Luiz Orlandi, Roberto Machado. Rio de Janeiro: Graal, 1988.

. (1969). The logic of sense. Versão para o inglês: Mark Lester. 1.ed. London: The Athlone Press, 1993.

DELEUZE, G.; GUATARRI, F. (1972). O anti-Édipo: capitalismo e esquizofrenia. Tradução: Luiz B. L. Orlandi. 2.ed. São Paulo: Editora 34, 2011.

. (1980a). Mil Platôs: capitalismo e esquizofrenia 2, vol.I. Tradução: Ana Lúcia de Oliveira, Aurélio Guerra Neto e Célia Pinto Costa. 2. ed. São Paulo: Editora 34, 2011.

. (1980b). Mil Platôs: capitalismo e esquizofrenia 2, vol.II. Tradução: Ana Lúcia de Oliveira, Aurélio Guerra Neto e Célia Pinto Costa. 2. ed. São Paulo: Editora 34, 2011.

. (1980c). Mil Platôs: capitalismo e esquizofrenia 2, vol.IV. Tradução: Suely Rolnik. 1.ed. São Paulo: Editora 34, 1997.

. (1992). Conversações. Tradução: Peter Pál Pelbart. 2.ed. São Paulo: Editora 34, 2010 . (1993). Crítica e Clínica. Tradução: Peter Pál Pelbart. 2. Ed. São Paulo: Editora 34, 2011.

GRASSI, E. Vico and Humanism: essays on Vico, Heidegger, and rhetoric. Nova York: Peter Lang, 1990.

LAUREANO, P.S. Capitalismo e produção de subjetividade no mundo contemporâneo: uma leitura crítica. Defesa: janeiro/2011. 140 páginas. Dissertação de Mestrado; Orientador: Carlos Augusto P. Junior. PUC-Rio, Rio de Janeiro, 2011. Disponível online em: http://www2.dbd.puc-rio.br/pergamum/biblioteca/php/mostrateses.php? open=1\&arqtese $=0912452 \_2011$ Indice.html

NIETZSCHE, F. (1886). Além do bem e do mal: prelúdio a uma filosofia do futuro. Tradução de Paulo César de Souza. 1.ed. São Paulo: Companhia das Letras, 1996. 
. (1887). Genealogia da moral. Tradução de Paulo César de Souza. 1.ed. São Paulo: Companhia das Letras, 1998.

SCHÖPKE, R. (2004) Por uma filosofia da diferença: Gilles Deleuze, o pensador nômade. 2.ed. Rio de Janeiro: Contraponto, 2012.

VICO, G. (1725) The New Science. 1.ed. Ithaca, New York: Cornell University Press, 1948.

202 VON BURG, A.B. Caught between History and Imagination: Vico's ingenium for a rhetorical renovation of citizenship. Philosophy and Rhetoric, Penn State University Press, vol. 43, n.I, p. 26-52, 2010. 